\title{
Cytotoxicity of a new hemostatic agent on human pulp fibroblasts in vitro
}

\author{
Mesut E. Odabaş ${ }^{1}$, Murat Ertük ${ }^{2}$, Çağdaş Çınar ${ }^{1}$, Tamer Tüzüner ${ }^{3}$, Özlem Tulunoğlu ${ }^{4}$ \\ ${ }^{1} \mathrm{PhD}$, University of Gazi, Faculty of Dentistry, Department of Pediatric Dentistry, Ankara, Turkey \\ ${ }^{2}$ Professor, University of Karadeniz Technical, Department of Microbiology and Clinical Microbiology, School of Medicine, \\ Trabzon, Turkey \\ ${ }^{3} \mathrm{PhD}$, University of Karadeniz Technical, Department of Pediatric Dentistry Trabzon, Turkey \\ ${ }^{4}$ Professor, University of Gazi, Faculty of Dentistry, Department of Pediatric Dentistry, Ankara, Turkey
}

\section{Correspondence:}

University of Gazi, Faculty of Dentistry,

Department of Pediatric Dentistry,

8. Cadde 82. Sokak 06510,

Emek Ankara-Turkey

mesut@gazi.edu.tr

Received: $29 / 03 / 2010$

Accepted: 26/08/2010

Odabaş ME, Ertürk M, Cinar C, Tüzüner T, Tulunoğlu O. Cytotoxicity of a new hemostatic agent on human pulp fibroblasts in vitro. Med Oral Patol Oral Cir Bucal. 2011 Jul 1;16 (4):e584-7.

http://www.medicinaoral.com/medoralfree01/v16i4/medoralv16i4p584.pdf

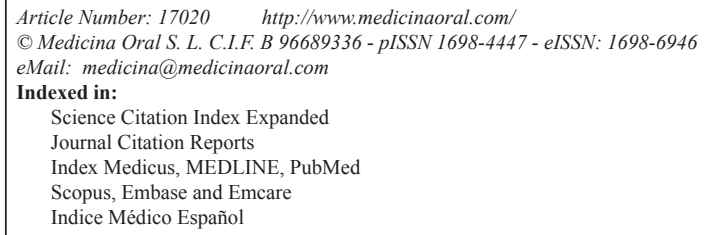

\begin{abstract}
Objective: The objective of this study was to evaluate the cytotoxicity of the plant extract ankaferd blood stopper (ABS) in vitro.

Study Design: ABS was eluted with fresh Dulbecco's Modified Eagle's Medium (DMEM) without serum for 72 $\mathrm{h}$, at $37^{\circ} \mathrm{C}$. The cells treated with various dilutions of ABS were seeded into 96 -well microplate at $10^{4} /$ well in triplicates. Cells without treatment served as a control group. The number of viable cells after $48 \mathrm{~h}$ incubation was determined by a modified 3-(4, 5-dimethyl-thiazol-2-yl)-2, 5-diphenyl-tetrazolium bromide (MTT) assay. The relative viability of pulp cells was expressed as color intensity of the number in the experimental wells relative to that of the control group. Absorbances were read at $570 \mathrm{~nm}$ on a microplate reader with a background subtraction at $620 \mathrm{~nm}$.

Result: The results showed that ABS was cytotoxic to human pulp fibroblasts by MTT assay.

Conclusions: The influence of cytotoxicity to human pulp fibroblasts depended on concentration of ABS. The more dilutions exhibited less cytotoxic characteristics compared to the more concentrated forms.
\end{abstract}

Key words: Cytotoxicity; hemostatic agent; pulp fibroblasts.

\section{Introduction}

The goal of vital therapy is to treat reversible pulpal injury and maintain pulp vitality and function. It includes two therapeutic approaches: indirect pulp capping in cases of deep dentinal cavities and direct pulp capping/ pulpotomy in cases of pulp exposures (1). Several factors influence the success of direct pulp capping/pulpotomy. One of the factors is control of pulp bleeding, which is necessary to improve the favourable prognosis of vital pulp therapy (2). If pulp bleeding can not be controlled, a blood clot on the wound surface would prevent intimate contact between the capping material and pulp tissue, thus provoking a choronic inflamatory response whilst impairing the healing process $(2,3)$.

Many hemostatic agents and procedures have been used to control pulpal bleeding in vital therapy. The most 
widespread technique is to control pulpal bleeding by applying mechanical pressure to the wound surface with a sterile cotton pellet. Another technique for controlling pulp bleeding is the application of hemostatic agents (ie, ferric sulphate).

Ankaferd Blood Stopper (ABS) (Ankaferd Sağlık Ürünleri A.Ş., İstanbul, Turkey) which is a folkloric medicinal plant extract that has been introduced for bleeding control in clinical health sciences (4). ABS produces hemostatic actions by providing the encapsulated protein network for vital phsiological erythrocyte aggregation. ABS has been safetly used in patients to treat epistaxis (5), after tonsillectomy (6) or variceal bleeding (7). In addition, ABS has been used to control upper gastrointestinal bleeding (8), life-threatening arterial bleeding of the digestive tract (9), and bleeding due to solitary rectal ulcer (10). Moreover, the levels of coagulation factors II, V, VIII, IX, X, XI, and XII were not affected by $\mathrm{ABS}$, therefore, $\mathrm{ABS}$ might be used in patients with deficient primary hemostasis (11).

The biologic and toxicologic properties of biomaterials are important for their clinical usage (12). In vitro cytotoxic screening as a primary factor of biocompatibility is determined by cell culture. The most appropriate cells (ie, cells homologous to the human tissues of ultimate concern) should be selected for in vitro toxicity tests (13). Moreover, pulp fibroblast are highly sensitive to toxic substances, indicating that pulp cells could be a sensitive barometer to reveal the possible adverse effects of dental materials $(13,14)$. The aim of this study was to evaluate the cytotoxicity of a new hemostatic agent on cultured human pulp fibroblast.

\section{Materials and Methods}

Ankaferd Blood Stopper derivates from different plants with names of Thymus vulgaris $(0.05 \mathrm{mg} / \mathrm{ml})$, Glycyrrhiza glabra $(0.07 \mathrm{mg} / \mathrm{ml})$, Vitis vinifera $(0.08 \mathrm{mg} / \mathrm{ml})$, Alpinia officinarum $(0.07 \mathrm{mg} / \mathrm{ml})$ and Urtica dioica $(0.06 \mathrm{mg} / \mathrm{ml})$.

Cell culture

The explant method was used to grow human dental pulp fibroblasts as described previously (15). The informed consent was obtained from the patients. Briefly, impacted human third molars were extracted and immediately after this procedure the root was removed by horizontal section below the cementoenamel junction with a number 330 bur at high speed with water spray. The pulp tissue was removed aseptically then was rinsed with Hank's Balanced Salt Solution (HBSS without serum) (Biological Industries, Israel), and placed in a $10-\mathrm{mm}$ glass Petri dish. Pulp tissue was cut into small fragments using surgical blades and tissue parts were picked up by a sterile needle to seed on to plastic surface inside a $T_{25}$ tissue culture flask (Greiner Bio-one, Germany). Dulbecco's Minimum Essential
Medium (DMEM) supplemented with $20 \%$ fetal calf serum (FCS) (Biochrom, Germany) and antibiotics (100 $\mathrm{U} \mathrm{mL}_{-}$penicillin, $100 \mu \mathrm{g} \mathrm{mL}-{ }_{1}$ streptomycin, and 0.25 $\mu \mathrm{g} \mathrm{mL}-$ fungizone) was used just enough amounts to keep the tissue parts wet. Cultures were maintained at $37^{\circ} \mathrm{C}$ in a humidified atmosphere of $5 \% \mathrm{CO}_{2}$ and 95 $\%$ air and increasing the volume of the medium every other day. After enough size of monolayer cells were grown around the tissue parts, the cells were detached with $0.25 \%$ trypsin (Sigma, USA) and $0.05 \%$ ethylenediaminetetraacetic acid (EDTA), and seeded into a fresh $T_{25}$ flask for subculture .Cell cultures of the third and fourth were used in this study.

Cytotoxicity assay

ABS supplied as in $2 \mathrm{ml}$ flacons was first diluted in duplicates in the range of 1:2-1:2028 using HBSS (without serum) in sterile eppendorf tubes. A total of $3 \times 10^{4}$ cells were placed into per dilution tube and preincubated for 30 minutes at $37^{\circ} \mathrm{C}$ humidified atmosphere with shaking ever 10 minutes. Cells treated with various dilutions of the ABS were then centrifuged at $1200 \mathrm{rpm}$ for $3 \mathrm{~min}$ and the cell pellet was resuspended in $0.6 \mathrm{ml}$ DMEM supplemented with $10 \%$ FCS and antibiotics. The cells treated with various dilutions of ABS were seeded into 96-well microplate at $10^{4} /$ well in triplicates. Cells without treatment served as a control group. The number of viable cells after $48 \mathrm{~h}$ incubation at $37^{\circ} \mathrm{C}$ in a humidified atmosphere of $5 \% \mathrm{CO}_{2}$ and $95 \%$ air was determined by the MTT assay as described (16). At the end of the incubation period, the medium with MTT was removed, and $100 \mu 1$ dimethylsulphoxide was added to each well. The plate was shaken on the microplate shaker to dissolve the blue MTT-formazan. The relative viability of pulp cells was expressed as color intensity of the number in the experimental wells relative to that of control. Absorbances were read at $570 \mathrm{~nm}$ on a microplate reader with background subtraction at $620 \mathrm{~nm}$.

Duplicates of each concentration were performed for each test. All assays were repeated three times to ensure reproducibility.

Statistical Analysis

Statistical analysis was done by one-way analysis of variance $(\mathrm{P}=.05)$ and Tukey multiple comparasion tests were used for analyzing absorbance values obtained by the MTT assay.

\section{Results}

The results showed that Ankaferd Blood Stopper (ABS) was cytotoxic to human pulp fibroblasts by MTT assay. The sensitivity of cytotoxicity to human pulp fibroblasts depended on concentration of material tested. The mean \pm sd relative viable cell numbers were given for all dilution groups in table 1 . 
Table 1. Survival and growth of human pulp fibroblasts as measured by MTT method after exposure to various dilution of ABS for 72 hours.

\begin{tabular}{|c|c|}
\hline Dilution (\%) & OD $_{\mathbf{5 7 0 ~} \mathbf{~ n m}}(\mathbf{m e a n} \pm \mathbf{s d})$ \\
\hline 100 & $0.000 \pm 0.000^{*}$ \\
\hline 50 & $0.021 \pm 0.017^{*}$ \\
\hline 12.5 & $0.027 \pm 0.019^{*}$ \\
\hline 6.125 & $0.034 \pm 0.002^{*}$ \\
\hline 3.125 & $0.167 \pm 0.021^{*}$ \\
\hline 1.562 & $0.150 \pm 0.002^{*}$ \\
\hline 0.781 & $0.245 \pm 0.247^{*}$ \\
\hline 0.390 & $0.381 \pm 0.010^{* *}$ \\
\hline 0.195 & $0.388 \pm 0.011^{* *}$ \\
\hline 0.097 & $0.406 \pm 0.015^{* *}$ \\
\hline 0.048 & $0.394 \pm 0.157^{* *}$ \\
\hline
\end{tabular}

Values with the same symbol are statistically similar by one-way ANOVA and Tukey multiple comparison tests $(\mathrm{P}>0.05)$.

\section{Discussion}

Many types of biomaterials have been utilized in dental practice procedures. Asssesing cytotoxicity based on several cytotoxicity testing methods is a necessary step in the evaluating the biocompatibility of all biomaterials. In vitro cytotoxity tests should be performed with cells homologous to the human tissue of ultimate concern (15). In addition, in vitro tests are simple, reproducible, cost-effective, relevant, and suitable for evaluating of basic biological properties of dental materials.

The dental pulp is essentially a connective tissue composed of fibroblast and odontoblast, with inherent capability to produce reperative dentin when the enviroment is favourable (17). The effective control of bleeding is necessary to improve favourable prognosis of vital therapy (2). A number of agents have been used to control pulpal hemorrhaging for this purpose. The most known technique to control pulpal bleeding is applying mechanical pressure to the wound surface with a sterile cotton pellet. Other techniques include the applying of mechanical pressure with pellets soaked in saline, hydrogen peroxide, sodium hypochlorite $(\mathrm{NaOCl})$, anesthetic solutions containing epinephrine, chlorhexidine or ferric sulphate (18-22). The application of $\mathrm{NaOCl}$ has been considered successful in adhesive pulp capping and has shown biocompatibility when used as a haemostatic agent $(21,23)$. However, a severe cytotoxic effect has been observed in cell cultures with $\mathrm{NaOCl}$, even in low concentrations (24). Ferric sulphate solution is also known to be cytotoxic and to cause tissue necrosis (25). The biocompatibility of chlorhexidine digluconate has not been determined completely (18). Consequently, for assessment of ABS cytotoxicity, human pulp fibroblasts were used to evaluate the cytotoxicity of ABS in this study.
The cytotoxity of ABS was evaluated with MTT assay in human pulp fibroblasts. Our results showed that ABS is cytotoxic to human pulp fibroblasts. The sensitivity of cytotoxicity to human pulp fibroblasts depended on concentration of material tested. The more dilutions exhibited less cytotoxic characteristics compared to the more concentrated forms.

One of the most commonly used hemostatic agents in dentistry is ferric sulphate which also has also been reported to show promising results as a dressing material for primary teeth pulpotomies (19). The agglutination of blood proteins results from the reaction of blood with ferric and sulphate ions. This ferric ion-protein complex mechanically seals the cut vessel and producing hemostasis. By forming plugs that occlude the capillary orifices, the protein complex also prevents the formation of blood clots and thereby minimizes chances for inflammation and internal resorption in pulp therapy $(3,26)$. The ABS mechanism involves formation of a protein network that acts as focal points for erythrocyte aggregation without affecting any individual clotting factor (4). Therefore, ABS may be a useful product in the management of pulpal bleeding during endodontic treatment of teeth. However, there are few clinical studies on the efficacy and safety of ABS.

On the other hand, de Menezes et al. (27) compared the cytotoxicity of pulpotomy agents. They found that ferric sulphate was about 332 and 32 times more toxic than mineral trioxide aggregate and calcium hydroxide, respectively. However, Peng et al. (28) presented a systematic review of the effects of formocresol and ferric sulphate when used as medicaments in pulpotomized primary molar teeth. They reported that the mean clinical and radiographic success rates of pulpotomy treatment with ferric sulphate were $91.6 \%$ and $73.5 \%$, respectively.

The ideal hemostatic agents also should be free of cytotoxicity, but the ability of hemostasis is more important; however, after hemostasis is achieved, unused hemostatic material should be eliminated, leaving as little hemostatic agent as possible in order to avoid postoperative complications (29).

Moreover, it should be discussed into a broader perspective that many materials such as peroxides for dental bleaching and bonding agents used in adhesive dentistry all demonstrate cytotoxicity in vitro (30), yet they form an important part of every dentist's restorative armamentarium.

In conclusion, cytotoxicity was detected for Ankaferd Blood Stopper by MTT assay. However, a combination of two or more sensitive and quantative methods for safety evaluation is necessary to avoid false-negative results for $\mathrm{ABS}$ at the preclinical stage. $\mathrm{ABS}$ needs to be evaluated further because concentration used and exposure time to the agent are important factors affecting the resulting effect. 


\section{References with links to Crossref - DOI}

\section{References}

1. Tziafas D. The future role of a molecular approach to pulp-dentinal regeneration. Caries Res. 2004;38:314-20.

2. Stanley HR. Pulp capping: conserving the dental pulp--can it be done? Is it worth it? Oral Surg Oral Med Oral Pathol. 1989;68:62839.

3. Schröder U. Effect of an extra-pulpal blood clot on healing following experimental pulpotomy and capping with calcium hydroxide. Odontol Revy. 1973;24:257-68.

4. Goker H, Haznedaroglu IC, Ercetin S, Kirazli S, Akman U, Ozturk Y, et al. Haemostatic actions of the folkloric medicinal plant extract Ankaferd Blood Stopper. J Int Med Res. 2008;36:163-70.

5. Meric Teker A, Korkut AY, Kahya V, Gedikli O. Prospective, randomized, controlled clinical trial of Ankaferd Blood Stopper in patients with acute anterior epistaxis. Eur Arch Otorhinolaryngol. 2010;267:1377-81.

6. Teker AM, Korkut AY, Gedikli O, Kahya V. Prospective, controlled clinical trial of Ankaferd Blood Stopper in children undergoing tonsillectomy. Int J Pediatr Otorhinolaryngol. 2009;73:1742-5.

7. Tuncer I, Doganay L, Ozturk O. Instant control of fundal variceal bleeding with a folkloric medicinal plant extract: Ankaferd Blood Stopper. Gastrointest Endosc. 2010;71:873-5.

8. Kurt M, Disibeyaz S, Akdogan M, Sasmaz N, Aksu S, Haznedaroglu IC. Endoscopic application of ankaferd blood stopper as a novel experimental treatment modality for upper gastrointestinal bleeding: a case report. Am J Gastroenterol. 2008;103:2156-8.

9. Kurt M, Kacar S, Onal IK, Akdogan M, Haznedaroglu IC. Ankaferd Blood Stopper as an effective adjunctive hemostatic agent for the management of life-threatening arterial bleeding of the digestive tract. Endoscopy. 2008;40 Suppl 2:E262.

10. Ibis M, Kurt M, Onal IK, Haznedaroglu IC. Successful management of bleeding due to solitary rectal ulcer via topical application of Ankaferd blood stopper. J Altern Complement Med. 2008;14:1073-4.

11. Cipil HS, Kosar A, Kaya A, Uz B, Haznedaroglu IC, Goker H, et al. In vivo hemostatic effect of the medicinal plant extract Ankaferd Blood Stopper in rats pretreated with warfarin. Clin Appl Thromb Hemost. 2009;15:270-6.

12. Mjör IA. Biologic assessment of restorative dental materials: interrelationship of biologic and technologic properties. Oper Dent. 1978:3:9-13.

13. Feigal RJ, Yesilsoy C, Messer HH, Nelson J. Differential sensitivity of normal human pulp and transformed mouse fibroblasts to cytotoxic challenge. Arch Oral Biol. 1985;30:609-13.

14. Van Wyk CW, Olivier A, Maritz JS. Cultured pulp fibroblasts: are they suitable for in vitro cytotoxicity testing? J Oral Pathol Med. 2001;30:168-77.

15. Chang YC, Huang FM, Cheng MH, Chou LS, Chou MY. In vitro evaluation of the cytotoxicity and genotoxicity of root canal medicines on human pulp fibroblasts. J Endod. 1998;24:604-6.

16. Mosmann T. Rapid colorimetric assay for cellular growth and survival: application to proliferation and cytotoxicity assays. J Immunol Methods. 1983;65:55-63.

17. Yamamura T. Differentiation of pulpal cells and inductive influences of various matrices with reference to pulpal wound healing. $\mathrm{J}$ Dent Res. 1985;64:530-40.

18. Thomas GP, Boyd JB, Soni NN, Palmer JE. Histologic study of pulp capping using chlorhexidine in dogs. NDA J. 1995;46:17-20.

19. Fei AL, Udin RD, Johnson R. A clinical study of ferric sulfate as a pulpotomy agent in primary teeth. Pediatr Dent. 1991;13:327-32.

20. Accorinte Mde L, Loguercio AD, Reis A, Muench A, de Araújo VC. Response of human pulp capped with a bonding agent after bleeding control with hemostatic agents. Oper Dent. 2005;30:14755 .

21. Hafez AA, Cox CF, Tarim B, Otsuki M, Akimoto N. An in vivo evaluation of hemorrhage control using sodium hypochlorite and direct capping with a one- or two-component adhesive system in exposed nonhuman primate pulps. Quintessence Int. 2002;33:261-72.
22. Tunç ES, Saroğlu I, Sari S, Günhan O. The effect of sodium hypochlorite application on the success of calcium hydroxide pulpotomy in primary teeth. Oral Surg Oral Med Oral Pathol Oral Radiol Endod. 2006;102:e22-6.

23. Costa CA, Edwards CA, Hanks CT. Cytotoxic effects of cleansing solutions recommended for chemical lavage of pulp exposures. Am J Dent. 2001;14:25-30.

24. Heling I, Rotstein I, Dinur T, Szwec-Levine Y, Steinberg D. Bactericidal and cytotoxic effects of sodium hypochlorite and sodium dichloroisocyanurate solutions in vitro. J Endod. 2001;27:278-80.

25. Larson PO. Topical hemostatic agents for dermatologic surgery. J Dermatol Surg Oncol. 1988;14:623-32.

26. Lemon RR, Steele PJ, Jeansonne BG. Ferric sulfate hemostasis: effect on osseous wound healing. Left in situ for maximum exposure. J Endod. 1993;19:170-3.

27. De Menezes JV, Takamori ER, Bijella MF, Granjeiro JM. In vitro toxicity of MTA compared with other primary teeth pulpotomy agents. J Clin Pediatr Dent. 2009;33:217-21.

28. Peng L, Ye L, Guo X, Tan H, Zhou X, Wang C, et al. Evaluation of formocresol versus ferric sulphate primary molar pulpotomy: a systematic review and meta-analysis. Int Endod J. 2007;40:751-7.

29. Tomizawa Y, Komori M, Takada K, Nishida H, Endo M, Kurosawa H. In Vitro and In Vivo Evaluation of the Biocompatibility and Cytotoxicity of Local Hemostatic Agents. Jpn J Car-diovasc Surg. 2004;33:382-6.

30. Darmani H, Al-Hiyasat AS, Milhem MM. Cytotoxicity of dental composites and their leached components. Quintessence Int. 2007;38:789-95. 